\title{
Study of Risk Preference, Investment Experience and Interpersonal Influence-An Empirical Analysis with Chinese Sample
}

\author{
Xiaoyuan $\mathrm{Chu}^{1,2}$, Yuan $\mathrm{Li}^{3}$, Jing $\mathrm{Han}^{1}$ \\ ${ }^{1}$ School of Economics and Resource Management, Beijing Normal University, Beijing, China \\ ${ }^{2}$ School of Risk and Actuarial Studies, Business School, the University of New South Wales, Sydney, Australia \\ ${ }^{3}$ Research Department, CIConsulting, Shenzhen, China \\ Correspondence: Xiaoyuan Chu, School of Economics and Resource Management, Beijing Normal University, Beijing, \\ China. E-mail: seancxy@126.com
}

This study was supported by China Scholarship Council (No. 201506040126).

Received: August 2, 2015

doi:10.11114/aef.v2i4.1181
Accepted: August 26, 2015

Available online: October 30, 2015

URL: http://dx.doi.org/10.11114/aef.v2i4.1181

\begin{abstract}
This study internalized investment experience on the basis of study of the influence of interpersonal influence on risk preference, and studied the relationship among the interpersonal influence, investment experience and risk preference. Based on the theoretical analysis, with first-hand data collection and using multiple regression models, the paper studied the intermediate effect of investment experience in the relationship between the interpersonal influence and risk preference. We draw on the following conclusions: (1) Investment experience plays a significant intermediate role between friends' influence and risk preference, and the mediating effect size is about $57.61 \%$. (2) Investment experience is a full intermediate variable between family's influence and risk preference. (3) Investment experience plays a significant intermediate role between coworkers/classmates' influence and risk preference, and the mediating effect size is about $55.09 \%$.
\end{abstract}

Keywords: Interpersonal influence; Investment experience; Risk preference; Mediate Effect

\section{Introduction}

It is found that mere repeated exposure of the individual to a stimulus object enhances his attitude toward it in Zajonc's research (Zjonc, 1968), which was named exposure effect thereafter. The exposure effect is denned as the increase in positive affect that results from the repeated presentation of unfamiliar stimuli (Harrison, 1977). And many research demonstrated this phenomena and exposure effect was found with different situations and materials, such as polygons or figures (Bornstein \& D'Agostino, 1992; Seamon et al., 1995; Willems \& Van der Linden, 2006), Chinese ideographs (Monahan, Murphy, \& Zajonc, 2000) photographs (Bornstein \& D'Agostino, 1992), pictures (Kruglanski, Freund, \& Bar-Tal, 1996). And many theories are established to explain this phenomena, such as opponent-process model (Harrison, 1977), perceptual fluency/ misattribution model (Bornstein \& D'Agostino, 1992), hedonic fluency model (Winkielman \& Cacioppo, 2001), uncertainty-reduction model (Lee, 2001), levels-of-processing model (Nordhielm, 2002).

It is indisputable that people would be influenced by others during the interaction and communication. Many empirical studies have tested the role of interpersonal influence in decision making and interpersonal influence does have an effect in preference of product (Childers and Rao, 1992; Harrison, Mykytyn, and Riemenschneider, 1997; Lu, Yao, and Yu, 2005; Bault, 2011; Tomlin, et al, 2013; Germar et al, 2014 ;). And several theories stress the importance of interpersonal influence on the decision or choice in everyday life, such as theory of planned behavior (Ajzen, Icek, 1991), two-step flow theory (Katz, Elihu.1957), and peer influence theory (Deutsch \& Gerard, 1955).

As mentioned above exposure would facilitate positive attitude and interpersonal influence has some effects on people's decision, whether similar effects can be found in the risk preference. And if both exposure to investment, which is investment experience to be specific, and interpersonal influence have some influences, what mechanism would be?

In order to answer the two questions, we establish an analytical framework for interpersonal influence, investment experience and risk preference to analyze their relationships. 
We hypothesize the following:

First, both investment experience and interpersonal influence have some effect on risk preference.

Second, interpersonal influence has some effect on investment experience.

Third, investment experience is a mediator between interpersonal influence and risk preference.

$$
\begin{gathered}
\operatorname{Pr} e=\beta_{0}+\sum \lambda_{1} I E+\varepsilon \\
\operatorname{Pr} e=\beta_{0}+\sum \lambda_{2} \operatorname{IpIn}+\varepsilon \\
I E=\beta_{0}+\sum \lambda_{3} \operatorname{IpIn}+\varepsilon \\
\operatorname{Pr} e=\beta_{0}+\sum \lambda{ }^{\prime}{ }_{1} I E+\sum \lambda{ }^{\prime}{ }_{2} \operatorname{IpIn}+\varepsilon
\end{gathered}
$$

With $\lambda_{1}, \lambda_{2}, \lambda_{3}$ are significant; and compared with $\lambda_{2}$, the statistical significance level of $\lambda^{\prime}{ }_{2}$ drops significantly. Where Pre is short for risk preference, IpIn is short for Interpersonal influence, IE is short for investment experience. The hypothesis of this study is shown in figure 1: Interpersonal influence has both direct and indirect influence on risk preference, while the indirect influence works through investment experience.

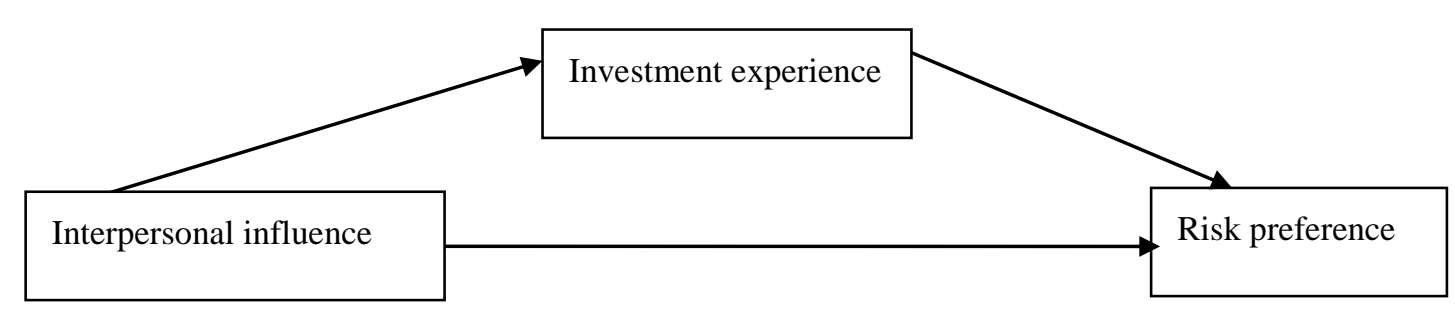

Figure 1. Theoretical relationship among interpersonal influence, investment experience and risk preference

\section{Methodology}

\subsection{Subjects of study}

Cluster sampling and convenient sampling methods were used for the investigation. 400 questionnaires were distributed in 12 corporations or institutions in Beijing, with 393 questionnaires returned and 387 valid. And another 173 questionnaires are collected from online survey, among which 162 are valid. And in total data from 549 subjects (male 318 , female 228 and 6 missing data in gender) are valid. The valid response rate is 95.81 .

\subsection{Research instrument}

Interpersonal influence: there are three dimensions in interpersonal influence: friends' influence, family members' influence and coworkers' influence or classmates' influence in this research. And each dimension includes two parts. Take friends' influence for example. Its sub-dimensions are proportion of friends who have invested in financial products and proportion of friends working in financial institution. This research applies a self-designed self-reporting questionnaire which divides proportion of friends/ family members/ coworkers or classmates who have invested in financial products into 5 grades, friends/ family members/ coworkers or classmates working in financial institution into 4 grades. And the influences of friends/ family members/ coworkers or classmates are calculated in the following formulas: $F r I n=Z[Z(F r W E)+Z(F r I E)]$, FaIn=Z[Z(FaWE) $+Z(F a I E)]$, CoIn=Z[Z(CoWE)+Z(CoIE)], among which FrIn is short for standard score of friends' influence; FrIE is short for standard score of proportion of friends who have invested in financial products; FrWE is short for standard score of proportion of friends working in financial institution; FaIn is short for standard score of family members' influence; FaIE is short for standard score of proportion of family members who have invested in financial products; FaWE is short for standard score of proportion of family members working in financial institution;;CoIn is short for standard score of coworkers' influence or classmates' influence; CoIE is short for standard score of proportion of coworkers/classmates who have invested in financial products; CoWE is short for standard score of proportion of coworkers/classmates working in financial institution; The same below. 
Investment experience: In this research we choose years of investment to indicate investment experience. And we divide years of investment into 5 grades: no investment experience, less than 1 year investment experience (with 1 year included), 1 to 5 years investment experience (with 5 year included), 5 to 10 years investment experience (with 10 year included) and more than 10 years investment experience.

Risk preference: there are two dimensions in risk preference: investment ratio to savings at present and plan for further investment in the future. And we divide investment ratio to savings into 5 grades: 0 , less than $0.3,0.3$ to $0.6,0.6$ to 1 and more than 1. And plan for further investment in the future has two levels. And risk preference is calculated in the following formulas $\operatorname{Pre}=\mathrm{Z}[\mathrm{Z}(\mathrm{I})+\mathrm{Z}(\mathrm{PI})]$, among which Pre is short for standard score of risk preference; $\mathrm{I}$ is short for standard score of investment ratio to savings at present; PI is short for plan for further investment; The same below.

\subsection{Research Process}

The questionnaires distributed in 12 corporations or institutions were administrated with the whole office as a group, employing group measurement under unified instructions. And the questionnaires, with no time limitation, were collected on the spot and checked one by one with invalid ones eliminated.

And the online questionnaires are distributed through email and weichat. And the subject can answer the questions with computer or cellphone with no time limitation. All the answers were collected automatically with information technology.

This research employed SPSS19.0 for statistical analysis, which includes analysis of variance, correlation analysis and analysis of regression.

\section{Results and Discussion}

\subsection{Relationship between risk preference and demographic variables}

Pearson's correlation was applied to calculate the correlation coefficients of the risk preference and demographic variables. The result is as followings:

(1) Risk preference is positively correlated with age;

(2) Risk preference is significantly correlated with marital status. Comparing with the unmarried, the married is higher in risk preference;

(3) Risk preference is significantly correlated with major. Subjects majoring in economics, finance or accounting tend to be higher in risk preference;

(4) No significant correlation is found in risk preference and education or gender.

Table 1. Correlation matrix of risk preference and demographic variables

\begin{tabular}{|c|c|c|c|c|c|c|c|c|}
\hline & Pre & I & PI & Gen & Age & MS & $\mathrm{Ed}$ & DE \\
\hline Pre & 1 & & & & & & & \\
\hline I & $.857^{* *}$ & 1 & & & & & & \\
\hline PI & $.857^{* *}$ & $.468^{* *}$ & 1 & & & & & \\
\hline Gen & .019 & .029 & .006 & 1 & & & & \\
\hline Age & $.178^{* *}$ & $.159^{* *}$ & $.148^{* *}$ & .077 & 1 & & & \\
\hline MS & $.231^{* *}$ & $.224^{* *}$ & $.172^{* *}$ & -.018 & $.658^{* *}$ & 1 & & \\
\hline Ed & .066 & .070 & .046 & $.209^{* *}$ & -.079 & -.050 & 1 & \\
\hline $\mathrm{DE}$ & $.097^{*}$ & .074 & $.093^{*}$ & .040 & .029 & .027 & $.158^{* *}$ & 1 \\
\hline
\end{tabular}

** and * indicate that the coefficient is significant at the 0.01 and 0.05 levels, respectively the same below.

Description: Gen is short for gender (female=-1, male=1); Age is short for age; MS is short for marital status (unmarried=-1, married=1); Ed is short for education; DE is short for majoring in economics, finance or accounting $($ no $=0$, yes $=1)$. The same below.

\subsection{Relationship between risk preference, investment experience and interpersonal influence}

Pearson's correlation was applied to calculate the correlation coefficients of the risk preference, interpersonal influence and investment experience. The result is as followings:

(1) Risk preference is significantly positively correlated with years of investment on financial products.

(2) Risk preference is significantly positively correlated with friends' influence as well as its two dimensions (proportion of friends who have invested in financial products and proportion of friends working in financial institution); 
(3) Risk preference is significantly positively correlated with family members' influence as well as one dimension (proportion of family members who have invested in financial products). While no significant correlation is found between risk preference and proportion of family members working in financial institution.

(4) Risk preference is significantly positively correlated with coworkers/classmates' influence as well as its two dimensions (proportion of coworkers/classmates who have invested in financial products and proportion of coworkers/classmates working in financial institution);

Table 2. Correlation matrix of risk preference, investment experience and interpersonal influence

\begin{tabular}{|c|c|c|c|c|c|c|c|c|c|c|c|c|c|}
\hline & Pre & I & PI & YoI & FaIn & FaIE & FaWE & CoIn & CoIE & CoWE & FrIn & FrIE & FrWE \\
\hline Pre & 1 & & & & & & & & & & & & \\
\hline I & $.857^{* *}$ & 1 & & & & & & & & & & & \\
\hline PI & $.857^{* *}$ & $.468^{* *}$ & 1 & & & & & & & & & & \\
\hline YoI & $.621^{* *}$ & $.565^{* *}$ & $.499^{* *}$ & 1 & & & & & & & & & \\
\hline FaIn & $.199^{* *}$ & $.165^{* *}$ & $.179^{* *}$ & $.280^{* *}$ & 1 & & & & & & & & \\
\hline FaIE & $.249^{* *}$ & $.216^{* *}$ & $.213^{* *}$ & $.324^{* *}$ & $.823^{* *}$ & 1 & & & & & & & \\
\hline FaWE & .079 & .055 & .082 & $.137^{* *}$ & $.823^{* *}$ & $.355^{* *}$ & 1 & & & & & & \\
\hline CoIn & $.346^{* *}$ & $.284^{* *}$ & $.310^{* *}$ & $.335^{* *}$ & $.456^{* * *}$ & $.426^{* *}$ & $.324^{* *}$ & 1 & & & & & \\
\hline CoIE & $.407^{* *}$ & $.335^{* *}$ & $.362^{* *}$ & $.422^{* *}$ & $.372^{* *}$ & $.457^{* *}$ & $.156^{* *}$ & $.810^{* *}$ & 1 & & & & \\
\hline CoWE & $.154^{* *}$ & $.126^{* *}$ & $.140^{* * *}$ & $.122^{* *}$ & $.365^{* *}$ & $.233^{* *}$ & $.368^{* *}$ & $.810^{* *}$ & $.312^{* * *}$ & 1 & & & \\
\hline FrIn & $.351^{* *}$ & $.299^{* *}$ & $.303^{* * *}$ & $.356^{* *}$ & $.464^{* *}$ & $.421^{* *}$ & $.343^{* *}$ & $.818^{* *}$ & $.657^{* *}$ & $.669^{* *}$ & 1 & & \\
\hline FrIE & $.394^{* *}$ & $.335^{* *}$ & $.342^{* *}$ & $.384^{* *}$ & $.423^{* *}$ & $.455^{* *}$ & $.241^{* *}$ & $.686^{* *}$ & $.766^{* *}$ & $.345^{* *}$ & $.832^{* *}$ & 1 & \\
\hline FrWE & $.189^{* *}$ & $.163^{* *}$ & $.162^{* *}$ & $.209^{* *}$ & $.349^{* *}$ & $.246^{* *}$ & $.329^{* *}$ & $.676^{* *}$ & $.327^{* *}$ & $.768^{* *}$ & $.832^{* *}$ & $.385^{* *}$ & 1 \\
\hline
\end{tabular}

Descreption: YoI is short for standard score of years of investment on financial products;

To better understand the impact of interpersonal influence on risk preference, regression analysis was conducted, with risk preference as predicted variable, demographic variables (age and gender) as control variables, and interpersonal influence factors (including proportion of friends who have invested in financial products, proportion of friends working in financial institution, proportion of family members who have invested in financial products, proportion of family members working in financial institution, proportion of coworkers/classmates who have invested in financial products, proportion of coworkers/classmates working in financial institution) as predictive variable. The stepwise regression results are as followings:

Table 3. Stepwise regression analysis of interpersonal influence on risk preference

\begin{tabular}{cccccc}
\hline Model & $\begin{array}{c}\text { Predictive } \\
\text { variable }\end{array}$ & Standardized $\beta$ & $\mathrm{T}$ & $\mathrm{P}$ & Adjusted R $^{2}$ \\
\hline 1 & (constant) & & .038 & .970 & .162 \\
& CoIE & .404 & 10.293 & .000 & .178 \\
2 & (constant) & & -2.996 & .003 & \\
& CoIE & .388 & 9.897 & .000 & .191 \\
& Age & .133 & 3.392 & .001 & \\
& (constant) & & -2.893 & .004 & \\
& CoIE & .243 & 4.058 & .000 & .001 \\
& Age & .127 & 3.273 & .002 & \\
\hline
\end{tabular}

As shown in the table above: two interpersonal influence factors (proportion of coworkers/classmates who have invested in financial products and proportion of friends who have invested in financial products) and age entered into the regression equation on risk preference, with a predictive power of $19.1 \%$. 


\subsection{Study of mediating effect of investment experience on risk preference}

\subsubsection{Mediating effect of investment experience on friends' influence and risk preference}

The mechanism of mediating effect of investment experience on friends' influence and risk preference reveals that friends' influence has a direct influence on subject's risk preference, and in the meantime, has an indirect influence on risk preference via investment experience. And in the relation between friends' influence and risk preference, the mediating effect size of investment experience is up to $57.61 \%$, which means that investment experience, as a partial mediator, plays an important role in the influencing process of friends' influence on risk preference. In another word, friends' influence affects one's risk preference, to a large extent, by affecting by affecting the investment experience of the subject. To be specific, subjects with more friends working in financial institutions or having investment experience are more likely to have longer investment history, which in turn induces more preference in financial products; on the contrary, subjects with less friends working in financial institutions or having investment experience tend to reject financial product due to their limited experience of investment. In other words, the promoting effect of friends' influence on risk preference is not fulfilled entirely in a direct way, but partially via the investment experience of the subject.

Table 4. Mediating effect of investment experience on friends' influence and risk preference

\begin{tabular}{lll} 
& Standardized regression equation & T test of regression coefficient \\
\hline First-step & Pre=0.351FrIn & risk preference $=0.040 \mathrm{t}=8.751^{* *}$ \\
Second-step & YoI=0.356FrIn & risk preference $=0.040 \mathrm{t}=8.900^{* *}$ \\
& Pre=0.568YoI+ & risk preference $=0.035 \mathrm{t}=16.044^{* *}$ \\
& 0.149 FrIn & risk preference $=0.035 \mathrm{t}=4.212^{* *}$ \\
\hline
\end{tabular}

The size of mediating effect is: $0.356 * 0.568 / 0.351=57.61 \%$

Description: FrIn is short for friends' influence, $\operatorname{FrIn}=\mathrm{Z}[\mathrm{Z}(\mathrm{FrWE})+\mathrm{Z}(\mathrm{FrIE})]$

3.3.2 Mediating effect of investment experience on family's influence and risk preference

The mechanism of mediating effect of investment experience on family's influence and risk preference reveals that family's influence has an indirect influence on risk preference via investment experience. In another word, family's influence affects one's risk preference by affecting investment experience of the subject. To be specific, subjects with more family member working in financial institutions or having investment experience are more likely to have longer investment history, which in turn induces more preference in financial products; on the contrary, subjects with less family members working in financial institutions or having investment experience tend to reject financial product due to their limited experience of investment. In other words, the promoting effect of family's influence on risk preference is indirect, via investment experience of the subject.

Table 5. Mediating effect of investment experience on family's influence and risk preference

\begin{tabular}{lll}
\hline & Standardized regression equation & T test of regression coefficient \\
\hline First-step & Pre=0.199FaIn & risk preference $=0.042 \mathrm{t}=4.747^{* *}$ \\
Second-step & YoI=0.280aIn & risk preference $=0.041 \mathrm{t}=6.819^{* *}$ \\
\multirow{2}{*}{ Third-step } & Pre=0.613YoI+ & risk preference $=0.035 \mathrm{t}=17.525^{* *}$ \\
& 0.027 FaIn & risk preference $=0.035 \mathrm{t}=0.785$
\end{tabular}

Investment experience is a full intermediate variable between family's influence and risk preference.

Description: FaIn is short for family's influence, $\mathrm{FaIn}=\mathrm{Z}[\mathrm{Z}(\mathrm{FaWE})+\mathrm{Z}(\mathrm{FaIE})]$

\subsubsection{Mediating effect of investment experience on coworkers/classmates' influence and risk preference}

The mechanism of mediating effect of investment experience on coworkers/classmates' influence and risk preference reveals that coworkers/classmates' influence has a direct influence on subject's risk preference, and in the meantime, has an indirect influence on risk preference via investment experience. And in the relation between coworkers/classmates' influence and risk preference, the mediating effect size of investment experience is up to 55.09\%, which means that investment experience, as a partial mediator, plays an important role in the influencing process of coworkers/classmates' influence on risk preference. In another word, coworkers/classmates' influence affects one's risk preference, to a large extent, by affecting the investment experience of the subject. To be specific, subjects with more coworkers/classmates working in financial institutions or having investment experience are more likely to have longer investment history, which in turn induces more preference in financial products; on the contrary, subjects with less coworkers/classmates working in financial institutions or having investment experience tend to reject financial product due to their limited experience of investment. In other words, the promoting effect of coworkers/classmates' influence 
on risk preference is not fulfilled entirely in a direct way, but partially via the investment experience of the subject.

Table 6. Mediating effect of investment experience on coworkers/classmates' influence and risk preference

\begin{tabular}{lll}
\hline & Standardized regression equation & T test of regression coefficient \\
\hline First-step & Pre=0.346CoIn & risk preference $=0.040 \mathrm{t}=8.619^{* *}$ \\
Second-step & YoI=0.335CoIn & risk preference $=0.040 \mathrm{t}=8.320^{* *}$ \\
& Pre=0.569YoI+ & risk preference $=0.035 \mathrm{t}=16.228^{* *}$ \\
& $0.156 \mathrm{CoIn}$ & risk preference $=0.035 \mathrm{t}=4.448^{* *}$ \\
\hline
\end{tabular}

The size of mediating effect is: $0.335 * 0.569 / 0.346=55.09 \%$

Description: CoIn is short for coworkers/classmates' influence, $\mathrm{CoIn}=\mathrm{Z}[\mathrm{Z}(\mathrm{CoWE})+\mathrm{Z}(\mathrm{CoIE})]$

\section{Conclusion}

Basing on the above analysis and discussion, a summary of the conclusion are as follows:

(1) Risk preference is significantly positively correlated with years of investment on financial products.

(2) Risk preference is significantly positively correlated with friends' influence as well as its two dimensions (proportion of friends who have invested in financial products and proportion of friends working in financial institution);

(3) Risk preference is significantly positively correlated with family members' influence as well as one dimension (proportion of family members who have invested in financial products). While no significant correlation is found between risk preference and proportion of family members working in financial institution.

(4) Risk preference is significantly positively correlated with coworkers/classmates' influence as well as its two dimensions (proportion of coworkers/classmates who have invested in financial products and proportion of coworkers/classmates working in financial institution);

(5) Investment experience plays a significant intermediate role between friends' influence and risk preference, and the mediating effect size is about $57.61 \%$.

(6) Investment experience is a full intermediate variable between family's influence and risk preference.

(7) Investment experience plays a significant intermediate role between coworkers/classmates' influence and risk preference, and the mediating effect size is about $55.09 \%$

\section{Reference}

Ajzen, I. (1991). The theory of planned behavior, Organizational Behavior and Human Decision Processes, 50(2), 179. http://dx.doi.org/10.1016/0749-5978(91)90020-T

Bault, N., Joffily, M., Rustichini, A., \& Coricelli, G.(2011) Medial prefrontal cortex and striatum mediate the influence of social comparison on the decision process. Proceedings of the National Academy of Sciences of the United States of America, 108(38), 16044-16049 http://dx.doi.org/10.1073/pnas.1100892108

Bornstein, R. F., \& D'Agostino, P. R. (1992). Stimulus recognition and the mere exposure effect. Journal of Personality and Social Psychology, 63, 545-552. http://dx.doi.org/10.1037/0022-3514.63.4.545

Childers, T., Rao, L., \& Akshay, R. (1992) The Influence of Familial and Peer-based Reference Groups on Consumer Decisions. Journal of Consumer Research, 19(2), 198. http://dx.doi.org/10.1086/209296

Deutsch, M. G., \& Harold, B. (1955) A study of normative and informational social influences upon individual judgment. The Journal of Abnormal and Social Psychology, 51(3), 629-636. http://dx.doi.org/10.1037/h0046408

Germar, M., Schlemmer, A., Krug, K., Voss, A., \& Mojzisch, A. (2014). Social Influence and Perceptual Decision Making. Personality and Social Psychology Bulletin, 40(2), 217-231. http://dx.doi.org/10.1177/0146167213508985

Harrison, A. A. (1977). Mere exposure. In L. Berkowitz (Ed.), Advances in experimental social psychology, 10, 39-83. New York: Academic Press. http://dx.doi.org/10.1016/s0065-2601(08)60354-8

Harrison, D. A., Mykytyn, Jr., Peter P. R., \& Cynthia, K. (1997). Executive Decisions about Adoption of Information Technology in Small Business: Theory and Empirical Tests, Information Systems Research, 8(2), 171-195 http://dx.doi.org/10.1287/isre.8.2.171

Katz, E. (1957). The Two-Step Flow of Communication: An Up-To-Date Report on an Hypothesis. The Public Opinion Quarterly, 2l(1), 61-78. http://dx.doi.org/10.1086/266687 
Kruglanski, A. W., Freund, T., \& Bar-Tal, D. (1996). Motivational effects in the mere-exposure paradigm. European Journal of Social Psychology, 26, 479-499. http://dx.doi.org/10.1002/(SICI)1099-0992(199605)26:3<479::AID-EJSP770>3.0.CO;2-U

Lee, A. Y. (2001). The mere exposure effect: an uncertainty reduction explanation revisited. Pers Soc Psychol Bull, 27, 1255-1266. http://dx.doi.org/10.1177/01461672012710002

Lu, J., Yao, J., \& Yu, C. S. (2005) Personal innovativeness, social influences and adoption of wireless Internet services via mobile technology. Journal of Strategic Information Systems, 14(3), 245-268. http://dx.doi.org/10.1016/j.jsis.2005.07.003

Monahan, J. L., Murphy, S. T., \& Zajonc, R. B. (2000).Subliminal mere exposure: Specific, general, and diffuse effects. Psychological Science, 11, 462-466. http://dx.doi.org/10.1111/1467-9280.00289

Nordhielm, C. (2002). The influence of level of processing on advertising repetition effects. Journal of Consumer Research, 29, 371-382. http://dx.doi.org/10.1086/344428

Seamon, J. G., Williams, P. C., Crowley, M. J., Kim, I. J., Langer, S. A., Orne, P. J., et al. (1995). The mere exposure effect is based on implicit memory: Effects of stimulus type, encoding conditions, and number of exposures on recognition and affect judgments. Journal of Experimental Psychology: Learning, Memory, and Cognition, 21, 711-721. http://dx.doi.org/10.1037/0278-7393.21.3.711

Tomlin, D., Nedic, A., Prentice, D., Holmes, P., Cohen, J. (2013) The Neural Substrates of Social Influence on Decision Making. PLoS One, 8(1), 1-11. http://dx.doi.org/10.1371/journal.pone.0052630

Willems, S., \& Van der Linden, M. (2006). Mere exposure effect: A consequence of direct and indirect fluency-preference links. Consciousness and Cognition, 15, 323-341. http://dx.doi.org/10.1016/j.concog.2005.06.008

Winkielman, P., \& Cacioppo, J. (2001). Mind at ease puts a smile on the face: Psychophysiological evidence that processing facilitation elicits positive affect. Journal of Personality and Social Psychology, 81, 989-1000. http://dx.doi.org/10.1037/0022-3514.81.6.989

Zajonc, R. B. (1968). Attitudinal effects of mere exposure. Journal of personality and social psychology, 9(2, Pt.2), 1-27. http://dx.doi.org/10.1037/h0025848

\section{(cc) EY}

This work is licensed under a Creative Commons Attribution 3.0 License. 